\title{
PROPOSTA DE METODOLOGIA DE ADEQUAÇÃO AO NOVO ACORDO ORTOGRÁFICO DA LÍNGUA PORTUGUESA PARA ESTUDANTES DO CURSO DE LICENCIATURA EM QUÍMICA DO IFRN- CURRAIS NOVOS
}

\author{
L. F. PEREIRA E T. MATIAS-FERREIRA JR. \\ Instituto Federal de Educação, Ciência e Tecnologia do Rio Grande do Norte - IFRN \\ tito.matias@ifrn.edu.br
}

Artigo submetido em agosto/2013 e aceito em agosto/2014

DOI: $10.15628 /$ holos.2014.1611

\section{RESUMO}

Este trabalho tem o intuito de dissertar sobre a importância de adequação ao novo acordo ortográfico da língua portuguesa para estudantes do curso de Licenciatura em Química do Instituto Federal do Rio Grande do Norte- Campus Currais Novos. Neste sentido, busca-se fazer um levantamento bibliográfico sobre este acordo, considerando suas características e importância para os estudantes e profissionais da área de educação. Objetiva-se ainda diagnosticar o nível de conhecimento sobre o tema que os discentes julgam possuir, bem como a importância que estes atribuem, e ainda, propor possíveis soluções de adequação ao acordo.

PALAVRAS-CHAVE: Acordo ortográfico, aprendizagem, linguística, interdisciplinaridade, extensão.

\section{THE PROPOSAL OF AN ADEQUATE METHODOLOGY OF THE NEW ORTHOGRAPHIC AGREEMENT OF THE PORTUGUESE LANGUAGE FOR CHEMISTRY UNDERGRATUATES AT IFRN-CURRAIS NOVOS}

\begin{abstract}
This paper aims at investigating the importance of the new orthographic agreement of the Portuguese language's adaptation to the teaching and learning process Chemistry undergraduate students at the Federal Institute of Rio Grande do Norte, Currais Novos Campus. In this sense, we make a survey of the literature on this agreement, considering its features and its importance to
\end{abstract}

students and professionals in the field of education. We also aim at diagnosing students' level of knowledge on the new orthographic agreement of the Portuguese language, as well as the importance they attribute to it to later propose possible solutions to the use of such an agreement in the field of Chemistry and Education.

KEYWORDS: New orthographic agreement of the Portuguese language, learning, Linguistics, interdisciplinarity, extension 


\section{INTRODUÇÃO}

O conhecimento da língua portuguesa é sem dúvida indispensável para potencializar a aprendizagem das disciplinas de cunho acadêmico, independente de quais áreas estas estejam elencadas. A Lei de Diretrizes e Bases da Educação Nacional (LDBEN), por meio do Inciso I do Art. 32 disserta que, no Ensino Fundamental, a formação básica do cidadão deve ocorrer mediante "I - o desenvolvimento da capacidade de aprender, tendo como meios básicos o pleno domínio da leitura, da escrita e do cálculo" (BRASIL, 2010, p. 26, grifos nossos). No que se refere ao ensino médio, também ocorre a preocupação com a importância da língua, colocando-a em lugar de destaque, conforme apontado pelo Inciso I do Art. 36 da LDBEN, uma vez que seu currículo deve vislumbrar "[...] a língua portuguesa como instrumento de comunicação, acesso ao conhecimento e exercício da cidadania [...]" (BRASIL, 2010, p. 29). No que compete ao ensino superior, de acordo com o inciso IV, Art. 43, deve-se promover a divulgação de conhecimentos culturais, científicos e técnicos que constituem patrimônio da humanidade e comunicar o saber através do ensino, de publicações ou de outras formas de comunicação (BRASIL, 2010).

Rodrigues (1997) orienta que todas as profissões que construíram ao longo do tempo o reconhecimento de um estatuto de profissionalidade plena (médicos, engenheiros, arquitetos, entre outros) se reconhecem, se afirmam e são distinguidas, em sua representação social, pela posse de um saber próprio, distinto e exclusivo do grupo que o partilha, produz e faz circular; conhecimento esse que legitima o exercício da função profissional em causa. Todavia, no que se refere aos docentes, espera-se que estes sejam portadores de conhecimentos além de sua disciplina específica, já que, aparentemente, exige-se que professores tenham conhecimentos interdisciplinares, sobretudo no que se refere à Língua Portuguesa.

Considerando a língua como instrumento comunicacional, Geraldi (1997) a define como um sistema organizado de sinais (signos) que serve como meio de comunicação entre os indivíduos. Em síntese, a língua é um código, um conjunto de signos, combinados através de regras, que possibilita ao emissor transmitir determinado discurso ao receptor. A comunicação, no entanto, concretiza-se quando emissor e receptor conhecem e dominam o código, que é utilizado de maneira preestabelecida e convencionada. Koch (2002), ao definir a concepção de língua como representação do pensamento, disserta que esta corresponde a de sujeito psicológico, individual, dono de sua vontade e de suas ações. Neste sentido, como esse sujeito é dono absoluto de seu dizer e de suas ações, o texto é visto como um produto - lógico - do pensamento do autor, nada mais cabendo ao leitor/ouvinte senão "captar" essa representação mental, juntamente com as intenções (psicológicas) do produtor, exercendo, pois, um papel essencialmente passivo. Travaglia (1997), considerando a língua como um processo de interação, define que o indivíduo ao fazer uso da língua não se limita a traduzir e exteriorizar um pensamento ou transmitir informações a outrem, mas sim realizar ações, agir, atuar sobre o interlocutor (ouvinte/leitor). Nesse contexto, a concepção interacionista da linguagem contrapõe-se às visões conservadoras da língua, que a tem como um objeto autônomo, sem história e sem interferência do social, já que não enfatizar esses aspectos não é condizente com a realidade na qual os indivíduos se inserem.

No que se refere à língua portuguesa, como se sabe, a mesma é representada por símbolos ortográficos. Define-se ortografia como uma convenção social que tem o objetivo de ajudar a comunicação escrita entre pessoas. Segundo Soares (2010), do século VI ao IX (período pré- 
histórico), o Português era apenas falado, não havendo inscrições que o exemplificassem. Do século IX ao XII (período proto-histórico), a língua passa a ter registro e do século XIII aos dias atuais (período histórico), a língua portuguesa começa a se definir e a apresentar as características da atualidade. O Português, especificamente, possuía, até 31 de dezembro de 2008, duas ortografias oficiais. Entretanto, o decreto de $n^{\circ} 6.538$ de 29 de setembro de 2008 promulgou o acordo ortográfico da língua portuguesa, assinado em Lisboa em 16 de dezembro de 1990, definindo ainda que tal acordo passaria a ter efeito a partir de $1^{\circ}$ de janeiro de 2009. A partir deste ponto, os falantes da língua deveriam definir estratégias para adequar-se da melhor maneira possível ao novo acordo ortográfico, tornando-o assunto de debates, discussões e, mais recentemente, motivo da criação de um novo decreto.

O fato é que este novo decreto deve ser de interesse, sobretudo dos profissionais da educação, uma vez que tais profissionais devem estar cientes do que um decreto desta magnitude pode impactar em sua profissão. Assim, necessita-se considerar alternativas de adaptação ao novo acordo ortográfico no processo de ensino-aprendizagem dos estudantes em geral, principalmente aos estudantes dos cursos de licenciatura, tendo em vista que estes serão futuros professores e, como tais, devem ter um bom domínio da língua portuguesa.

\section{MATERIAIS E MÉTODOS}

Para este trabalho foram pesquisadas literaturas de diversos tipos, tais como: livros, artigos, decretos, entre outros, que tratam do novo acordo ortográfico da língua portuguesa, seu histórico e suas implicações. Aplicou-se, também, um questionário estatístico censitário contendo cinco questões fechadas em escala visando diagnosticar a importância que os estudantes de licenciatura em Química do IFRN-Currais Novos dão a língua portuguesa e ao novo acordo ortográfico, bem como quantificar o conhecimento que tais estudantes julgam possuir a respeito do acordo ortográfico da Língua Portuguesa. Por fim, considerando toda a abrangência que a temática possui, sugere-se mecanismos que possam contribuir para um aperfeiçoamento dos discentes no que se refere especificamente a esta temática.

\section{RESULTADOS E DISCUSSÃO}

Segundo Brasil (2009), a existência de duas ortografias oficiais da língua portuguesa, a lusitana e a brasileira, tem sido considerada como largamente prejudicial para a unidade intercontinental do português e para o seu prestígio no mundo. Tal situação remonta a 1911, já que neste ano foi adotada em Portugal a primeira grande reforma ortográfica. Porém, esta reforma não foi extensiva ao Brasil. Partindo deste período, várias discussões e debates foram realizados a fim de elaborar acordos e decretos que unificassem a língua portuguesa falada no mundo. Um dos mais recentes deles, aprovado em 16 de Dezembro de 1990, teve seu decreto publicado em 29 de setembro de 2008, o decreto $n^{\circ}$ 6.538. Em seu artigo segundo, o decreto $n^{\circ} 6.538$ define a implementação do novo acordo ortográfico da língua portuguesa, obedecendo ao período de transição de $1^{\circ}$ de janeiro de 2009 a 31 de dezembro de 2012, durante o qual coexistiriam a norma ortográfica atualmente em vigor e a nova norma estabelecida. Entretanto, em 28 de dezembro de 2012, o Brasil publica um novo decreto estabelecendo como período de transição $1^{\circ}$ de Janeiro de 2013 a 31 de dezembro de 2015, fazendo com que o novo acordo ortográfico entre em vigor a partir de $1^{\circ}$ de janeiro de 2016. 
A extensão da data de vigência do novo acordo ortográfico da língua portuguesa no Brasil traz a tona um dito popular amplamente propagado em todo território nacional: "Brasileiro deixa tudo pra última hora". Contudo, este ditado popular não pode ser uma característica de profissionais, sobretudo da área de educação, diretamente envolvidos com a implementação do novo acordo ortográfico no Brasil. Para Libâneo (2002), existem novas atitudes docentes a serem cumpridas pelo professor, entre elas, assumir o ensino como mediação: aprendizagem ativa do aluno com a ajuda pedagógica do professor; modificar a ideia de uma escola e de uma prática pluridisciplinar para uma escola e uma prática interdisciplinar; conhecer estratégias do ensinar a pensar, ensinar a aprender a aprender; persistir no empenho de auxiliar os alunos a buscarem uma perspectiva crítica dos conteúdos, a se habituarem a apreender as realidades enfocadas nos conteúdos escolares de forma crítico-reflexiva. Sobre o valor e a aplicabilidade da interdisciplinaridade, Fazenda (1992) destaca que pode ser verificado tanto na formação geral, profissional, de pesquisadores, como meio de superar a dicotomia ensino-pesquisa e como forma de permitir uma educação permanente. Dentro deste conceito de interdisciplinaridade, de adaptação aos novos conteúdos, destaca-se a importância de preparar os licenciados das disciplinas em geral, mas aqui especificamente os de Química, para se prepararem desde sua formação inicial com estes conceitos. Um exemplo de conteúdo que encaixa-se perfeitamente nestas perspectivas é o acordo ortográfico da língua portuguesa. É fundamental que profissionais da educação tenham um bom domínio da língua portuguesa. Guedes e Souza (2011) pontuam que ler e escrever são tarefas da escola, questões para todas as áreas, uma vez que são habilidades indispensáveis para a formação de um estudante. Não pode-se esperar que questões de Língua Portuguesa sejam ensinadas apenas por profissionais desta área. É fundamental que o professor enquanto profissional, independente de sua especificidade, seja capaz de formar o aluno como cidadão.

Entretanto, no que se refere ao domínio da língua portuguesa, nota-se que os cursos de licenciatura em Química têm apresentado deficiências no que refere a sua matriz curricular, sobretudo pelo fato de desconsiderar atualmente o novo acordo ortográfico da língua portuguesa. Neste sentido, foi realizado um questionário de parâmetro com todos os estudantes do curso de Licenciatura em Química do IFRN-Currais Novos, regularmente matriculados, dos 3‥, 5‥, 6‥ e 8ㅇ. períodos, visando diagnosticar a importância do ensino e aprendizagem do novo acordo ortográfico da língua portuguesa por tais alunos e as possíveis dificuldades apresentadas pelos mesmos sobre tal temática. O questionário foi composto por cinco questões objetivas, fechadas em escala, seguindo as etapas sugeridas por Labes (1998): a realização da pesquisa; a elaboração do questionário; o teste; a sua distribuição e aplicação; a tabulação dos dados e análise e interpretação dos dados. 0 questionário alcançou $83 \%$ dos alunos matriculados no curso. A partir da coleta destas respostas, puderam-se verificar informações inovadoras e relativamente preocupantes. O tratamento de dados foi feito de forma criteriosa, analisando cada uma das respostas a fim de se fazer um diagnóstico preciso e eficaz da relevância do novo acordo ortográfico da língua portuguesa para os alunos de Licenciatura em Química do IFRN-Currais Novos.

A primeira questão questionou os alunos sobre importância atribuída aos conhecimentos de Língua Portuguesa para a profissão de professor. Os resultados podem ser observados na figura 1. 


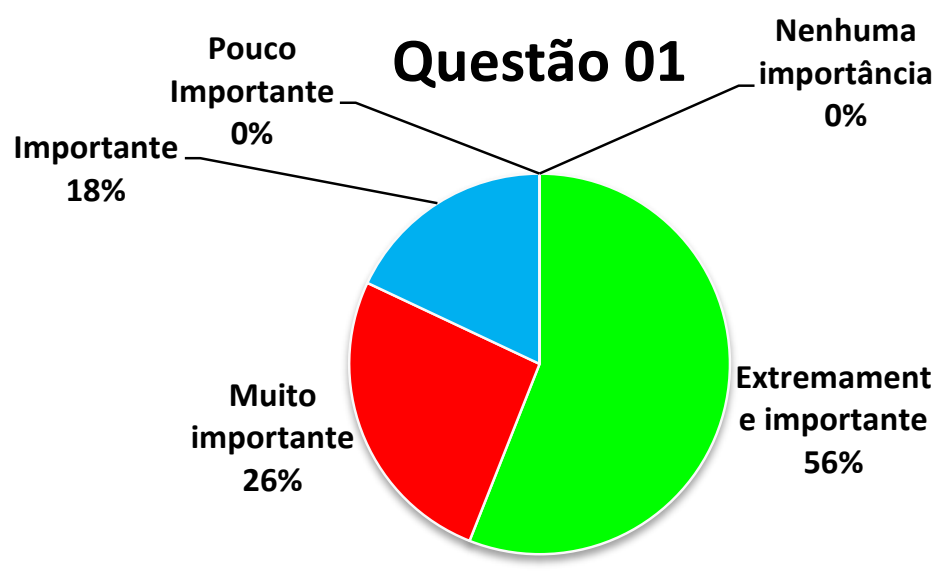

Figura 1 - Importância de Língua Portuguesa para professores

Como se percebe no gráfico, nenhum dos entrevistados considerou sem importância o conhecimento linguístico da língua portuguesa e todos deram alguma importância, sendo que a maioria considerou extremamente importante o conhecimento do Português para sua futura profissão. Com efeito, segundo Dionísio e Bezerra (2001), até pouco tempo pensava-se que as habilidades básicas no uso da língua limitavam-se a falar-ouvir, ler-escrever, mas hoje se sabe que isso não é suficiente. Existe a necessidade de aprender a ver e representar, bem como interpolar algo entre a fala e a escrita, fazendo com que esse contínuo fique ainda mais fluido. A Língua portuguesa é, neste sentido, extremamente importante para a função de professor.

A figura 2 trata da síntese das respostas a mais uma pergunta feita aos alunos. Aqui, questionou-se a importância que os discentes atribuem ao domínio do novo acordo ortográfico para a profissão docente.

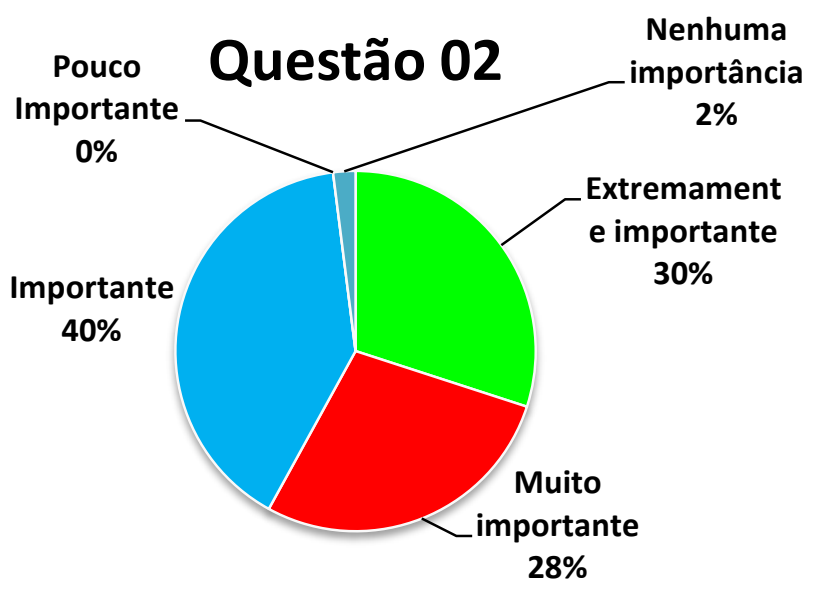

Figura 2 - Importância do acordo ortográfico para os docentes

Neste ponto, percebe-se um gráfico relativamente contraditório em relação ao primeiro, uma vez que o percentual de entrevistados que consideraram extremamente importante os conhecimentos de Língua Portuguesa diminui e o dos que consideravam apenas importante aumentou significativamente. Este fato evidencia a total falta de relação que os discentes fazem 
da língua portuguesa com a sua ortografia. Para Carraher (1992), escrever corretamente significa fazer um uso consciente e premeditado de nossa língua, o erro não é mais do que o desconhecimento ou a não consciência dessa arbitrariedade convencional e, a partir de um ponto de vista educativo, deve-se motivar a busca de metodologia mais adequada para garantir a aprendizagem. A ortografia é, portanto, indissociável da Língua Portuguesa, tal como somar e subtrair é da matemática, como os elementos químicos são da Química. Entretanto, lamentávelmente, o ensino de ortografia não evoluiu como os outros aspectos do ensino da Língua Portuguesa (Pellegrini, 2002). Talvez por esta razão essa desassociação tenha sido diagnosticada. Ainda assim, 98\% dos entrevistados deram importância ao novo acordo ortográfico e apenas $2 \%$ nenhuma importância.

A questão de número três perguntou os alunos se eles consideram satisfatória a matriz curricular do curso de Química no que se refere a Língua Portuguesa. A síntese dos resultados podem ser observada na figura 3 , um tratamento dos resultados mostrado em porcentagem.

\section{Questão 03}

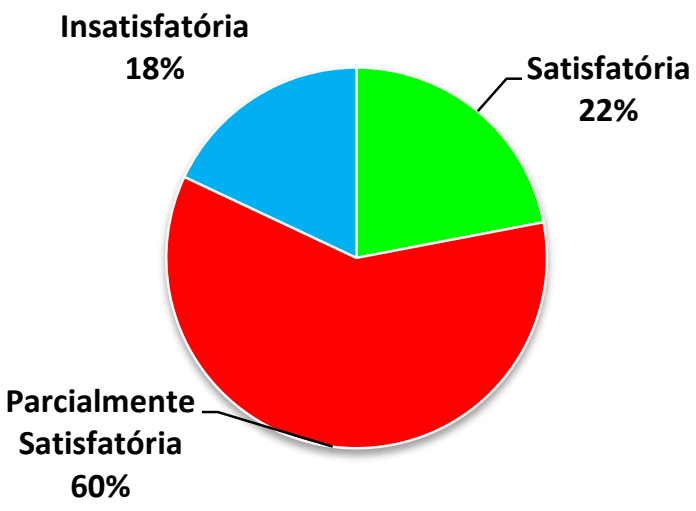

Figura 3 - Qualidade da Matriz Curricular do curso de Química no que se refere a Língua Portuguesa

A terceira questão traz uma informação muito importante. Dos entrevistados, $60 \%$ consideraram a Matriz Curricular do curso de Química apenas parcialmente satisfatória. Este é um fato extremamente preocupante. Um professor não pode estar meio preparado, possuir conhecimento ou não, haja vista que não se escreve ou se ensina meio certo. Para Holly \& McLoughlin (1989), os professores têm que se assumir como produtores da "sua" profissão. Sabese, todavia, que em nosso contexto educacional não é suficiente somente mudar o profissional; é preciso mudar os contextos em que ele intervém; mudando as matrizes curriculares para que sejam adequadas às necessidades do graduando, neste caso, o de Licenciatura em Química.

A quarta questão indagou os entrevistados sobre o nível de conhecimento de Língua Portuguesa que estes julgam ter para desempenhar sua profissão. 


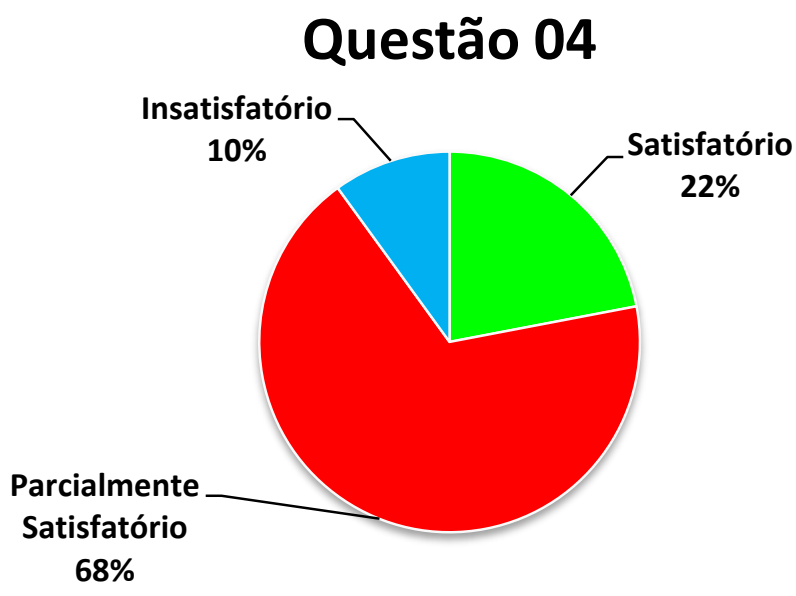

Figura 4 - Conhecimento de Língua Portuguesa dos Alunos de Química

Por meio da figura 4, percebe-se uma relação direta entre a Matriz Curricular e o conhecimento de Língua Portuguesa que os alunos julgam possuir. Em ambas as questões, os entrevistados se mostraram apenas parcialmente contemplados com o conhecimento linguístico. Neste sentido, deve-se ter o cuidado de valorizar a forma utilizada para se profissionalizar um professor de química em formação inicial. Souza (2007) declara que é importante entender que a profissão de professor caracteriza-se como uma profissão com níveis de complexidade, exigindo revisão e constante construção de saberes; centrando seu saber ser e saber fazer numa prática reflexiva e investiva do trabalho educativo e escolar, no cotidiano pessoal e profissional. As matrizes Curriculares devem passar por constantes revisões e construções para que os resultados possam ser potencializados ao final de cada formação.

A última questão, sintetizada na figura 5, estruturalmente traz em seu formato a síntese desta pesquisa, já que visou diagnosticar o conhecimento sobre o novo acordo ortográfico da língua portuguesa que os licenciandos julgam possuir.

\section{Questão 05}

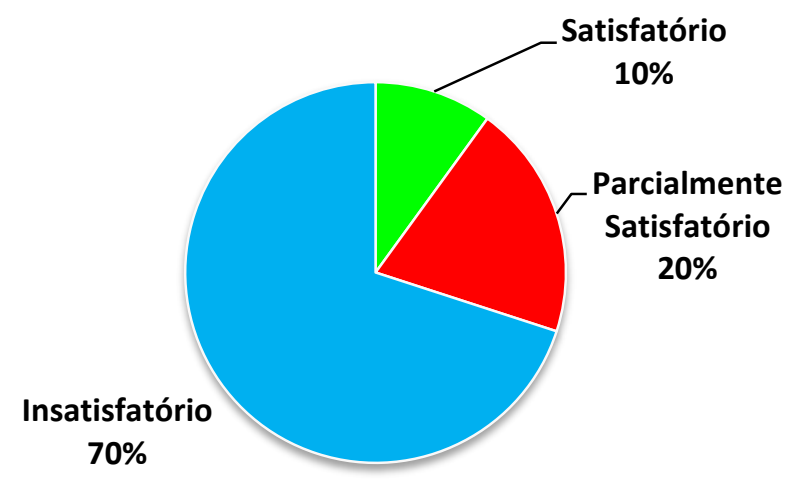

Figura 5 - Conhecimento sobre o novo acordo ortográfico licenciandos em Química

Muito embora o resultado desta última pergunta não tenha sido surpreendente, é digno de atenção. Dos entrevistados, a grande maioria, setenta por cento, afirmaram não possuir 
conhecimento satisfatório sobre o novo acordo ortográfico e vinte por cento apenas conhecimento parcial. Muito embora adiado, este acordo entrará em vigor em breve. É de fundamental importância que professores e professores em formação tenham domínio desta temática para que suas aulas sejam pautadas nestas novas regras. Uma mudança de escrita tem que partir de profissionais da educação para que assim sucessivamente as outras áreas sejam alcançadas de tal modo que tais mudanças sejam implantadas na sociedade de maneira simples e suscinta.

Academicamente, existem maneiras viáveis de se implantar esta temática, seja por palestras, debates e/ou cursos de extensão. A proposta de um curso de extensão universitária com carga horária satisfatória pode viabilizar aos estudantes de Licenciatura em Química do IFRNCurrais Novos o conhecimento sobre o novo acordo ortográfico da língua portuguesa. Ademias, para o Fórum de Pró-Reitores de Extensão das Universidades Públicas Brasileiras e SESU / MEC, a extensão universitária é um processo educativo que articula o ensino e a pesquisa de forma indissociável e viabiliza a relação transformadora entre universidade e a sociedade. Sendo assim, a extensão é uma via de mão dupla com trânsito assegurado à comunidade acadêmica, que encontrará na sociedade a oportunidade da elaboração da práxis de um conhecimento acadêmico, uma vez que este fluxo, que estabelece a troca de saberes sistematizados / acadêmico e popular, tendo como consequência a mudança de conhecimento acadêmico e a participação efetiva da comunidade na atuação da universidade. Uma vez implementado o curso de extensão "Novo Acordo Ortográfico da Língua Portuguesa para estudantes do Seridó/RN", ministrado por acadêmicos da Licenciatura em Química do IFRN-Currais Novos, estudantes do Seridó poderão aplicar as novas regras em seus trabalhos acadêmicos, não tendo a necessidade de estudar tais regras somente quando a obrigatoriedade do novo acordo ortográfico de língua portuguesa seja implantada.

\section{CONCLUSÕES}

Espera-se que o profissional de educação seja indutor de mudanças na sociedade, sobretudo, mudanças educacionais. Neste sentido, é atribuição do professor adequar-se ao novo acordo ortográfico da Língua Portuguesa para que este possa preparar a sociedade de forma geral. Os cursos de graduação, por sua vez, devem ter competência para preparar estes profissionais de forma adequada pelos meios que lhe são viáveis. Este trabalho mostrou as deficiências e anseios do curso de Graduação de Licenciatura em Química do IFRN-Currais Novos e propõe que seja implantado o curso de extensão universitária "Novo Acordo Ortográfico da Língua Portuguesa para estudantes do Seridó/RN" com o intuito de potencializar o preparo destes profissionais para o mercado de trabalho. Incentiva-se, ainda, pesquisas nesta área buscando outros diagnósticos e ainda outras formas de abordagem e implementação do novo acordo ortográfico da língua portuguesa para alunos de licenciaturas em geral e também para os alunos de Licencitatura em Química do IFRN-Currais Novos. Destaca-se que este trabalho não possui o objetivo de corrigir as deficiências que os alunos possuem no que se refere à Língua Portuguesa, haja vista que este é um processo contínuo que vai se desenvolvendo no decorrer da vida acadêmica destes, ainda por se tratar de uma área bastante abrangente que vai além da gramática e da ortografia. No entanto, deve-se ressaltar que a execução das propostas aqui discutidas é indubitavelmente um meio para que os graduandos encontrem-se norteados a buscar mecanismos para suprir suas deficiências no que se refere a esta disciplina. 


\section{AGRADECIMENTOS}

Ao PIBID (CAPES/CNPq) pelo apoio acadêmico e financeiro. Ao Instituto Federal de Educação, Ciência e Tecnologia do Rio Grande do Norte (IFRN) pelo corpo docente que está sempre à disposição para auxiliar seus discentes em geral.

\section{REFERÊNCIAS}

1. BRASIL. Lei de Diretrizes e Bases da Educação Nacional: lei no 9.394, de 20 de dezembro de 1996, que estabelece as diretrizes e bases da educação nacional. 5. ed. Brasília, DF: Câmara dos Deputados; Edições Câmara, 2010. (Série Legislação, n. 39). Disponível em: http://bd.camara.gov.br/bd/bitstream/handle/bdcamara/2762/ldb_5ed.pdf . Acesso em: 16 jun. 2013.

2. BRASIL. Plano Nacional de Extensão Universitária. http://www20.fcm.unicamp.br/extensão /arquivos/pne.pdf Acesso em: 29 de Jun. 2013.

3. BRASIL. Senado Federal. Secretaria Especial de Editorações e Publicações. Acordo ortográfico da língua portuguesa. Brasília: Senado Federal, 2009. 86 p.

4. CARRAHER, Terezinha Nunes. Explorações sobre o desenvolvimento da ortografia em português. Psicologia: Teoria e pesquisa, Brasília, V.1, n.1, pág. 269-285, 1985.

5. DIONÍSIO, Ângela Paiva \& BEZERRA, Maria Auxiliadora (orgs.). (2001) O livro didático de português: múltiplos olhares. Rio de Janeiro: Lucerna.

6. FAZENDA. Ivani. Integração e Interdisciplinaridade no Ensino Brasileiro: Efetividade ou ideologia? São Paulo: Loyola, 1992.

7. GERALDI, J. W. Da redação à produção de textos. In: GERALDI, J. W. \& CITELLI, B. Aprender e ensinar com textos de alunos. São Paulo: Cortez, v. 1, 1997b

8. HOLLY, Mary Louise \& MCLOUGHLIN, Caven S. (eds.). Perspectives on Teacher Professional Development. Lewes: The Falmer Press, 1989.

9. $\mathrm{KOCH}$, Ingedore G. Desvendando os segredos do texto. São Paulo: Contexto, 2002.

10. LABES, E. M. Questionário: do planejamento à aplicação na pesquisa. Chapecó: Grifos, 1998.

11. LIBÂNEO, José Carlos. Adeus professor, adeus professora? : novas exigências educativas e profissão docente. José Carlos Libâneo. - 6. ed.- São Paulo : Cortez, 2002.

12. PELLEGRINI, Tânia. Português-Palavra e arte. São Paulo: Atual, 2002

13. RODRIGUES, Maria de Lourdes. Sociologia das profissões. Oeiras: Celta, 1997.

14. SOUZA, E.C. "Cartografia histórica: trilhas e trajetórias da formação de professores". Revista da Faeeba: Educação e Contemporaneidade, v. 12, n. 20. p. 431-46, julho-dezembro de 2003, Salvador.

15. TRAVAGLIA, L. C. Gramática e Interação: uma proposta para o ensino de gramática no 1 e 2으. graus. São Paulo: Cortez, 1997. 